\title{
A RETROSPECTIVE STUDY OF INTESTINAL OBSTRUCTION PATIENTS IN AGMC \& GBP HOSPITAL, TRIPURA
}

Nilotpal Chakma1, Biswaraj Sarkar², Pradip Sarkar ${ }^{3}$

${ }_{1}^{1}$ Assistant Professor, Department of Surgery, AGMC \& GB Pant Hospital.

${ }^{2}$ Senior Resident, Department of Surgery, AGMC \& GB Pant Hospital.

${ }^{3}$ Associated Professor, Department of Surgery, AGMC \& GB Pant Hospital.

\section{ABSTRACT}

\section{BACKGROUND}

Acute intestinal obstruction is one of the major causes of morbidity \& mortality. Its management is still a challenge to surgeons in spite of advances in the field of medical sciences.

The aim of this study is to highlight the causes of intestinal obstruction in this geographical area and also other patient related relevant factors like age, sex, previous surgeries, presenting symptoms, type of surgeries performed, post-operative complications \& mortalities.

\section{MATERIALS AND METHODS}

This retrospective study was conducted at Department of Surgery of AGMC \& GB Pant Hospital, Agartala, Tripura from November 2012 to November 2016. A total of 87 patients presenting to Surgery Department with acute intestinal obstruction \& who underwent operative management were included in this study.

\section{RESULTS}

The study group comprised of 87 cases of acute intestinal obstruction in age group of above 12 years. The common age group affected was 41-50 years, common sex was male, the commonest cause of acute intestinal obstruction in this study was adhesion \& band (41.4\%) followed by malignancy (26.4\%). The other causes of intestinal obstruction are obstructed hernia (9.2\%), volvulus (6.9\%), stricture (5.7\%), ileocecal tuberculosis (3.4\%), superior mesenteric artery thrombosis (3.4\%). The most common operation performed was adhesiolysis (39\%) followed by resection \& anastomosis $(17.2 \%)$ and the most common post-operative complication observed was wound infection (29.9\%). The mortality in this study was $9.2 \%$.

\section{CONCLUSION}

Our study observed that adhesive intestinal obstruction is the most common cause of bowel obstruction followed by malignant bowel obstructions. Intestinal obstructions due to obstructed hernia are reduced because of practice of elective hernia surgery. Successful outcome in the management of acute intestinal obstruction mostly depends upon general condition of patients, early diagnosis \& skilful perioperative management.

\section{KEYWORDS}

Intestinal Obstruction, Adhesion \& Band, Malignancy, Obstructed Hernia, Adhesiolysis.

HOW TO CITE THIS ARTICLE: Chakma N, Sarkar B, Sarkar P. A retrospective study of intestinal obstruction patients in AGMC \& GBP Hospital, Tripura. J. Evolution Med. Dent. Sci. 2016;5(103):7531-7533, DOI: 10.14260/Jemds/2016/1705

\section{BACKGROUND \\ Intestinal obstruction refers to a situation when the intestinal contents cannot be forced further in aboral direction. Transit of intestinal content depends not only on an intact state of intestinal lumen, but also on peristalsis. ${ }^{1}$ Intestinal obstruction is one of the major causes of morbidity \& mortality. ${ }^{2}$ It is a frequently encountered problem in abdominal surgery that requires immediate admission. Manifestations of intestinal obstruction can range from a fairly good appearance with only slight abdominal discomfort and distention to a state of hypovolaemic or septic shock (or both) requiring an emergency operation. ${ }^{3}$ Intestinal obstruction may be of acute}

Financial or Other, Competing Interest: None.

Submission 07-12-2016, Peer Review 19-12-2016,

Acceptance 21-12-2016, Published 26-12-2016.

Corresponding Author:

Dr. Nilotpal Chakma,

AGMC \& G. B. Pant Hospital,

Agartala-799006,

West Tripura.

E-mail:drchakma@gmail.com

DOI: $10.14260 /$ jemds $/ 2016 / 1705$

\section{cc) $(i)$}

or chronic onset. It may be classified as dynamic obstruction (mechanical obstruction) or adynamic obstruction (paralytic ileus and pseudo-obstruction). It may also be classified as small bowel and large bowel obstruction. 4 The diagnostic and therapeutic approach to bowel obstruction should be systematic. The main aetiology of obstruction is of varied ranging from adhesions which account for $75 \%$ of cases of small bowel obstruction; the other causes include hernias, malignant bowel obstruction, inflammatory bowel disease, internal hernias, volvulus and strictures. ${ }^{5}$

This retrospective study was conducted in patients operated for acute intestinal obstruction in Surgery Department of AGMC \& GBP Hospital to highlight the common causes of intestinal obstruction and other patient related relevant factors like age, sex, previous surgeries, presenting symptoms, type of surgeries performed, post-operative complications \& mortalities.

\section{MATERIALS AND METHODS}

This retrospective study was conducted at Department of Surgery of AGMC \& GB Pant Hospital, Agartala, Tripura from 
November 2012 to November 2016. A total of 87 patients presenting to Surgery Department with acute intestinal obstruction \& who underwent operative management were included in this study. The patients who managed conservatively $\&$ the patients below 12 years (Paediatric age group) were excluded from the study.

Data collection included a detailed record of the patient's history, physical examination, and necessary investigations like baseline, X-ray abdomen erect and supine in all cases, ultrasound abdomen, barium studies, CT scan abdomen in some cases were recorded based on the requirement for each case.

The records of each patient with age, sex, symptoms, past surgical and medical history, diagnostic workup, aetiology of obstruction, operative information, morbidity and mortality and the final outcome of the patients were recorded in a predesigned proforma.

\section{RESULTS}

During the 4-year study period, 87 patients underwent operative management with exclusion of paediatric age group (age below 12 years) and others who were treated conservatively.

Age and sex distribution was in the ratio 1.2:1 (male: female) (Table-1) and the age distribution showed that most common occurrence of intestinal obstruction was in the age group of 41-50 years (27.6\%) (Table-2).

Abdominal pain was the most common presenting complaint (100\%) (Table-3) and the most common type of obstruction is small bowel obstruction (Table-4).

Adhesions \& bands were the most common cause of intestinal obstruction (41.4\%) followed by malignancy (26.4\%). The other causes of intestinal obstruction are obstructed hernia $(9.2 \%)$, volvulus $(6.9 \%)$, stricture $(5.7 \%)$, ileocaecal tuberculosis (3.4\%), superior mesenteric artery thrombosis (3.4\%) (Table-5).

Adhesiolysis was the most common type of surgery performed $((39 \%)$ followed by resection \& anastomosis $(17.2 \%)$ (Table-6) and the most common post-operative complication observed was wound infection (29.9\%) (Table-7).

In our study, the mortality rate was $9.2 \%$ ( 8 patients). All of eight patients had expired due to development of multiorgan failure in the postoperative period because of sepsis (4 patients), compartment syndrome (2 patients), respiratory infection ( 1 patient), and anastomotic leak (1 patient).

\begin{tabular}{|c|c|}
\hline Sex & No. of Patients (Percentage) \\
\hline Male & $48(55.2 \%)$ \\
\hline Female & $39(44.8)$ \\
\hline \multicolumn{2}{|c|}{ Table 1. Sex Distribution } \\
\hline
\end{tabular}

\begin{tabular}{|c|c|}
\hline Age Group (Years) & No. of Patients \\
\hline $12-20$ & 08 \\
\hline $21-30$ & 05 \\
\hline $31-40$ & 16 \\
\hline $41-50$ & 24 \\
\hline $51-60$ & 20 \\
\hline $61-70$ & 10 \\
\hline $71-80$ & 04 \\
\hline \multicolumn{2}{|c|}{ Table 2. Age group Distribution } \\
\hline
\end{tabular}

\begin{tabular}{|c|c|}
\hline Complaints & No. of Patients \\
\hline Abdominal pain & $87(100 \%)$ \\
\hline Vomiting & $75(86.2 \%)$ \\
\hline Abdominal distension & $72(82.7 \%)$ \\
\hline Constipation & $72(82.7 \%)$ \\
\hline \multicolumn{2}{|c|}{ Table 3. Presenting Complaints }
\end{tabular}

\begin{tabular}{|c|c|}
\hline Type & No. of Patients \\
\hline Small intestine & $64(73.6 \%)$ \\
\hline Large intestine & $23(26.4 \%)$ \\
\hline \multicolumn{2}{|c|}{ Table 4. Type of Bowel Obstruction } \\
\hline
\end{tabular}

\begin{tabular}{|c|c|}
\hline Cause & No. of Patients \\
\hline Adhesion \& band & $36(41.4 \%)$ \\
\hline Malignancy & $23(26.4 \%)$ \\
\hline Obstructed hernia & $08(9.2 \%)$ \\
\hline Volvulus & $06(6.9 \%)$ \\
\hline Stricture & $05(5.7 \%)$ \\
\hline Ileocaecal tuberculosis & $03(3.4 \%)$ \\
\hline SMA thrombosis & $03(3.4 \%)$ \\
\hline Miscellaneous & $03(3.4 \%)$ \\
\hline Table 5. Cause of Intestinal Obstruction
\end{tabular}

\begin{tabular}{|c|c|}
\hline Type of Surgery & No. of Patients \\
\hline Adhesiolysis & $34(39 \%)$ \\
\hline Resection \& anastomosis & $15(17.2 \%)$ \\
\hline Resection \& ostomy & $11(12.6 \%)$ \\
\hline Hemicolectomy & $08(9.2 \%)$ \\
\hline Diversion colostomy & $10(11.5 \%)$ \\
\hline Hernia repair & $04(4.6 \%)$ \\
\hline Loop ileostomy & $02(2.3 \%)$ \\
\hline Stricturoplasty & $01(1.1 \%)$ \\
\hline Others & $02(2.3 \%)$ \\
\hline Table 6. Type of Surgery Performed
\end{tabular}

\begin{tabular}{|c|c|}
\hline $\begin{array}{c}\text { Type of Post-Operative } \\
\text { Complications }\end{array}$ & No. of Patients \\
\hline Wound infection & $26(29.9 \%)$ \\
\hline Respiratory infection & $12(13.8 \%)$ \\
\hline Ostomy related complication & $06(6.9 \%)$ \\
\hline Sepsis & $05(5.7 \%)$ \\
\hline Compartment syndrome & $04(4.6 \%)$ \\
\hline Anastomotic leak & $03(3.4 \%)$ \\
\hline Burst abdomen & $02(2.3 \%)$ \\
\hline Table 7. Type of Post-operative Complications \\
\hline
\end{tabular}

\section{DISCUSSION}

Acute intestinal obstruction is a major cause of morbidity and financial expenditure in hospitals around the world. It accounts for $15 \%$ of all emergency department visits for acute abdominal pain. ${ }^{6}$ The aetiology varies. However, adhesions appear to be the most common cause in the Western world as well as in parts of Asia and Middle East.7,8 In our study also, adhesions \& band remain the most common cause of intestinal obstruction.

There is slight gender discrepancy in our patients with males outnumbering females which can be possibly accounted for obstructed inguinal hernia and malignant disease of the gastrointestinal tract that are more common in males as compared to females.

The majority of our study group presented with acute mechanical small bowel obstruction. This has also been found in other studies with small bowel obstruction accounting for about $80 \%$ of total obstruction cases. 9,10 
The mortality and morbidity in our study was high compared to other similar studies.7,8 Most of our patients were from a poor socioeconomic status with a high prevalence of malnutrition, therefore, the morbidity and mortality are likely to be higher.

\begin{tabular}{|c|c|c|c|}
\hline Author & Year & $\begin{array}{l}\text { Total } \\
\text { No. of } \\
\text { Case }\end{array}$ & $\begin{array}{l}\text { Most Common } \\
\text { Cause }\end{array}$ \\
\hline Present study & 2016 & 87 & $\begin{array}{l}\text { Adhesions and } \\
\text { bands }\end{array}$ \\
\hline $\begin{array}{c}\text { S. } \\
\text { Thirumuruganand } 11\end{array}$ & 2016 & 50 & $\begin{array}{c}\text { Adhesive band } \\
\text { obstruction }\end{array}$ \\
\hline Goyal SK 12 & 2015 & 150 & $\begin{array}{c}\text { Adhesions \& } \\
\text { bands }\end{array}$ \\
\hline Sinha S13 & 2002 & 97 & Adhesions \\
\hline Arshad M14 & 2010 & 229 & $\begin{array}{l}\text { Intestinal } \\
\text { tuberculosis }\end{array}$ \\
\hline Souvik Adhikary 5 & 2010 & 367 & Adhesions \\
\hline Madziga AG15 & 2008 & 376 & $\begin{array}{l}\text { Obstructed } \\
\text { hernia }\end{array}$ \\
\hline
\end{tabular}

\section{CONCLUSION}

In this study, we have found that adhesive intestinal obstruction is a common cause of bowel obstruction and increased the incidence of malignant bowel obstructions. Intestinal obstructions due to obstructed hernia are reduced because of practice of elective hernia surgery. Successful outcome in the management of acute intestinal obstruction mostly depends on general condition of patients, early diagnosis \& skilful perioperative management.

\section{Acknowledgements}

The authors would like to thank the Principal of AGMC \& GBP Hospital, Agartala, Tripura, India for allowing publication of the data.

\section{REFERENCES}

1. Hulin. Pathophysiology. Illustration Albin Brunovsky 1996. Bratislava, SAP 1997:696s.
2. Houghton SG, De la Medina AR, Sarr MG. Bowel obstruction. In: Maingot's abdominal operations. $11^{\text {th }}$ edn. Zinner MZ, Ashley SW, (edr). Chapter 17. New York: McGraw-Hill Medical 2007:479-505.

3. Hussain F, Fareez SN, Parveen S. Intestinal obstruction-a retrospective study. IOSR 2015;14(1):111-6.

4. Ellis BW, Patterson-Brown S. Hamilton and baileys emergency surgery. 14th edn. London: Arnold 2003.

5. Adhikari S, Hossein MZ, Das A, et al. Etiology and outcome of acute intestinal obstruction: a review of 367 patients in Eastern India. Saudi Journal of Gastroenterology 2010;16(4):285-7.

6. Irvin TT. Abdominal pain: a surgical audit of 1190 emergency admissions. Br J Surg 1989;76(11):1121-5.

7. Chen XZ, Wei T, Jiang $K$, et al. Etiological factors and mortality of acute intestinal obstruction: a review of 705 cases. Zhong Xi Yi Jie He Xue Bao 2008;6(10):1010-6.

8. Mohamed AY, al-Ghaithi A, Langevin JM, et al. Causes and management of intestinal obstruction in a Saudi Arabian hospital. J R Coll Surg Edinb 1997;42(1):21-3.

9. Renzulli P, Krahenbuhl L, Sadowski C, et al. Modern diagnostic strategy in ileus. Zentralbl Chir 1998;123(12):1334-9.

10. Wysocki A, Krzywon J. Causes of intestinal obstruction. Przegl Lek 2001;58(6):507-8.

11. Thirumuruganand S, Chelladurai S, Sankar MS. A retrospective study of acute intestinal obstruction and its management in our institution. IAIM 2016;3(7):302-9.

12. Goyal SK, Chhabra UK, Bansal SK, et al. Intestinal obstruction-a retrospective study of 150 cases. IAIM 2016;3(3):29-34.

13. Sinha S, Kaushik R, Yadav TD, et al. Mechanical bowel obstruction: the Chandigarh experience. Trop Gastroenterol 2002;23(1):13-5.

14. Malik AM, Shah M, Pathan R, et al. Pattern of acute intestinal obstruction: is there a change in the underlying etiology. Saudi J Gastroenterol 2010;16(4):272-4.

15. Madziga AG, Nuhu AI. Causes and treatment outcome of mechanical bowel obstruction in north eastern Nigeria. West Afr J Med 2008;27(2):101-5. 